\title{
Correction to: A Study on the Optimization of Joint Mandrel Shape for Manufacturing Long Type Elbow Using Push Bending Process
}

\author{
Yea-Jin Yang ${ }^{1} \cdot$ Choon-Man Lee $^{1}$
}

Published online: 8 February 2021

c) Korean Society for Precision Engineering 2021

\section{Correction to: \\ International Journal of Precision Engineering and Manufacturing \\ https://doi.org/10.1007/s12541-020-00443-4}

During the correction process unfortunately the author photos in the biography section have been interchanged. The correction biographies should be as follows:

The original article has been corrected.

Publisher's Note Springer Nature remains neutral with regard to jurisdictional claims in published maps and institutional affiliations.

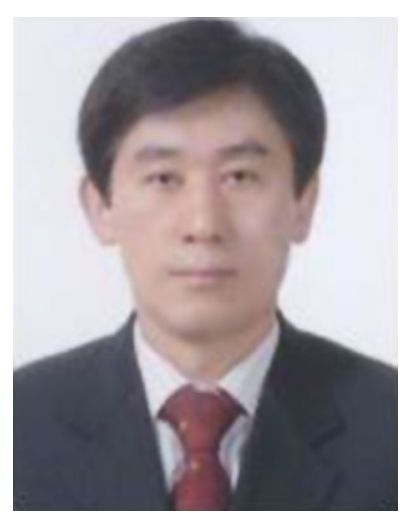

Choon-Man Lee Professor in the school of mechanical engineering at Changwon National University. His research interests include computer aided manufacturing, machine tool, production engineering, laser-assisted machining and hybrid manufacturing.

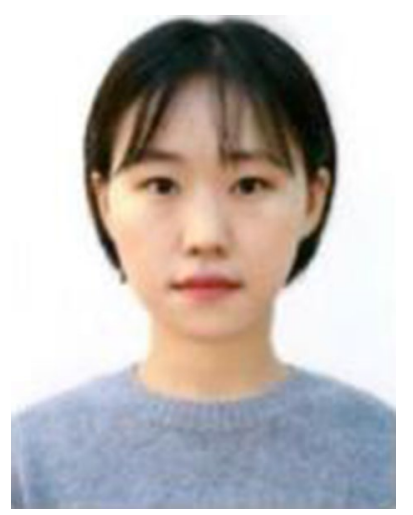

Yea-Jin Yang She received the M.S. degree in mechanical engineering from Changwon National University. Her research interests include the laser-assisted machining and hybrid manufacturing technologies.
The original article can be found online at https://doi.org/10.1007/ s12541-020-00443-4.

Choon-Man Lee

cmlee@changwon.ac.kr

Yea-Jin Yang

yejin6436@naver.com

1 School of Mechanical Engineering, Changwon National

University, \#9 Sarim-dongGyeongsangnam-do,

Changwon-si 641-773, Republic of Korea 